\title{
Photodegradation and Photostabilization of Poly(3-Hydroxybutyrate)
}

\author{
Renate Maria Ramos Wellen ${ }^{a *}$, Eduardo Luís Canedo ${ }^{a, b}$, Marcelo Silveira Rabello ${ }^{b}$,
}

Guilhermino José Macêdo Fechine ${ }^{c}$

\author{
${ }^{a}$ Department of Materials Engineering, Federal University of Paraiba - UFPB, 58051-900, \\ João Pessoa, PB, Brazil \\ ${ }^{b}$ Department of Materials Engineering, Federal University of Campina Grande - UFCG, 58429-140, PB, Brazil \\ ${ }^{c}$ Graphene and Nano-materials Research Center, MackGraphe, Mackenzie Presbyterian University, \\ 01302-907, São Paulo, SP, Brazil
}

Received: November 3, 2015; Revised: March 2, 2016; Accepted: April 26, 2016

\begin{abstract}
The present work is concerned with the photodegradation and photostabilization of poly(3hydroxybutyrate) (PHB) biopolymer. Two commercial grades of PHB were investigated, containing of $4.0 \%$ and $6.2 \%$ of hydroxyvalerate $(\mathrm{HV})$ comonomer, named $\mathrm{PHB}_{1}$ and $\mathrm{PHB}_{2}$, respectively. Injection moulded specimens were exposed to ultraviolet radiation (UV-A) in the laboratory for periods of up to 12 weeks and then characterized by tensile testing, surface appearance, size exclusion chromatography (SEC), and scanning electron microscopy (SEM). The exposure to UV radiation caused great damaged on the surface color, reduction of molecular size and mechanical properties. The effects were more pronounced on $\mathrm{PHB}_{2}$, probably due a lighter surface color and less packed macromolecular structure which facilitates the transmission of light throughout the samples. Specimens of $\mathrm{PHB}_{1}$ were also injected with the addition of a UV absorber and antioxidant, resulting in a higher UV stability of PHB, as shown by a low reduction in molar mass and better mechanical properties.
\end{abstract}

Keywords: Biodegradable polymers, PHB, ultraviolet radiation, photodegradation, photostabilization

\section{Introduction}

Considering that the plastic-made products are in the center of many debates related to environmental issues, a current trend of the polymer community is the study of ways to reduce the environmental impact of these products ${ }^{1-5}$. Besides the development of materials with a better recyclability, the use of biodegradable polymers and plastics obtained from renewable sources are some of the main objectives to achieve this goal. Committed to this purpose, we have been investigating the poly (3-hydroxybutyrate) (PHB) which is a natural and aliphatic polyester obtained from renewable sources. Our works have been focused on its phase transformation, crystallization and melting, stress cracking, mechanical, thermal and optical properties ${ }^{6-9}$. PHB used in the present work was produced from sugar cane plants, and was synthesized by biotechnological processes (microbial fermentation) without environmental damages.

PHB is inherently a non-toxic material and it is considered biocompatible, being used in medical applications like prosthesis, suture threats and devices for drugs release inside the human body ${ }^{10-11}$. The general uses of PHB in replacement of ordinary plastics are growing, including applications like packing and other short life products like cups and cutleries for fast food restaurants. Due to its biodegradability, when discarded PHB can be attacked by microorganisms such as bacteria, and fungus which might be able to destroy its macromolecular chains producing $\mathrm{CO}_{2}, \mathrm{CH}_{4}, \mathrm{H}_{2} \mathrm{O}$ and microcellular organisms.

* e-mail: wellen.renate@gmail.com
These components return to the environment and could be used in another PHB's synthesis, in a typical life cycle of PHB. These characteristics make PHB a very promising material and efforts on establishing its properties, extending its applications, and optimizing its processing conditions are reported in the literature ${ }^{12-16}$

Among the several possibilities of PHB application, we foresee the production of longer life consumer products. This assumption is based on the fact that the mechanical properties of this polymer are similar to usual polymers like polystyrene or polypropylene. If the product is not used or stored under conditions to withstand biodegradation, the lifetime could be compatible to the aimed application. Under this situation, the product can be exposed to ultraviolet radiation and, like the other types of polymers, suffer from this weathering condition. The photodegradation behavior of PHB, and the stabilization strategies, is scarcely reported in the literature ${ }^{17}$. The main objective of this work is to investigate the effects of ultraviolet radiation on PHB with different contents of hydroxyvalerate (HV) comonomers. Injection moulded specimens were exposed to weathering cycles of UV radiation, temperature and condensed water (humidity). The exposure procedure followed ASTM G-155 to simulate day (UV lights on) and night (UV lights off with water condensation $)^{18,19}$. The effect of exposure was analyzed by scanning electron microscopy (SEM), tensile tests, and molecular weight. The use of stabilizing additives was also investigated. 


\section{Experimental}

\subsection{Materials and specimen preparation}

Two random copolymers of 3-hydroxybutyrate (HB) with different contents of 3-hydroxyvalerate (HV) were used in the present study, both supplied by PHB Industrial SA (Brazil):

- $\quad$ FE-141, with 4\% of HV, melt flow rate MFR 23-25 $\mathrm{dg} / \mathrm{min}$ (ASTM D $1238,190^{\circ} \mathrm{C} / 2.16 \mathrm{~kg}$ ), and number average molar weight $M_{n} 52 \mathrm{~kg} / \mathrm{mol}$.

- $\quad$ FE-112 with $6.2 \%$ of $\mathrm{HV}$, MFR $30-33 \mathrm{dg} / \mathrm{min}$ (ASTM D1238, $190^{\circ} \mathrm{C} / 2.16 \mathrm{~kg}$ ), $M_{n} 76.2 \mathrm{~kg} / \mathrm{mol}$.

The resins were coded as $\mathrm{PHB}_{1}$ and $\mathrm{PHB}_{2}$, respectively. In an attempt to evaluate the effect of stabilizing additives, a UV absorber Tinuvin 791FB $(0.25 \%)$ and an antioxidant Irganox B215 (0.40\%) were added to $\mathrm{PHB}_{1}$; this material was coded $\mathrm{PHB}_{\mathrm{ABS}}$. The amount of additives was chosen based on manufacturer's recommendation. The chemicals structures of HB and HV units are shown in Figure 1.

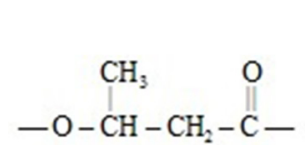

(a)

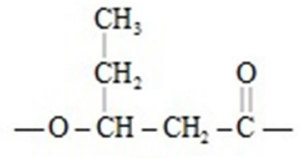

(b)
Figure 1: Structural units of 3-hydroxybutyrate HB (a) and 3-hydroxyvalerate HV (b).

Type I (ASTM D-638) tensile test specimen of $\mathrm{PHB}_{1}$, $\mathrm{PHB}_{2}$ and $\mathrm{PHB}_{\mathrm{ABS}}$ were produced in a Romi 130 injection molding machine, operating with barrel temperature ranging between $150-190^{\circ} \mathrm{C}$ and the mold at $20^{\circ} \mathrm{C}$.

\subsection{Methods}

The exposure to ultraviolet (UV) radiation was done with the tensile tests specimens for up to 12 weeks in an accelerated weathering chamber Q-Lab, type QUV, containing UV-Afluorescent tubes. These lamps have a maximum irradiance of $0.89 \mathrm{~W} / \mathrm{m}^{2}$ at $340 \mathrm{~nm}$. The weathering cycles were: 8 hours under UV light at $60^{\circ} \mathrm{C}$ and 4 hours in the dark under condensed water at $50^{\circ} \mathrm{C}$. The exposure procedure carried out according to ASTM G-155.

Molecular weight analyses were conducted by size exclusion chromatography (SEC) using a Viscotek HT-GPC equipment at $40^{\circ} \mathrm{C}$ with a refractive index detector. Samples used for SEC analysis were removed from the surface (up to $1 \mathrm{~mm}$ ) of the tensile test specimen directly exposed to UV radiation. The polymer was dissolved in chloroform and the filtered solution was injected into the equipment. The solvent flow rate was $1 \mathrm{~mL} / \mathrm{min}$ and the columns were calibrated with narrow molecular weight PS.

Mechanical tests were done in accordance to ASTM D638 at $20 \mathrm{~mm} / \mathrm{min}$ at $23^{\circ} \mathrm{C}$, using an EMIC model DL2000 universal testing machine with load cell of $5 \mathrm{kN}$. The results reported represent averages of at least four test samples.

Scanning electron microscopy images of fractured surface were taken in a JEOL 6460, the samples were cryogenically fractured in liquid nitrogen and covered with carbon to avoid the charge accumulation.
The crystallinity degree of the exposed surface of samples was obtained by X-ray diffraction in a Rigaku-Dairix Miniflex II equipment using $\mathrm{Cu} \mathrm{K} \alpha$ radiation $(1.54 \AA)$, and a scattering angles range of $2 \theta=4-90^{\circ}$ at a rate of $3 \% \mathrm{~min}$.

\section{Results and Discussion}

Photographs of $\mathrm{PHB}_{1}$ and $\mathrm{PHB}_{2}$ sample tests unexposed and exposed to UV radiation for 6 and 12 weeks are showed in Figure 2. The exposed surfaces, previously brown and caramel, turned into caramel and whitish, respectively, after 12 weeks under UV exposure. According to previous works done by one of the current authors ${ }^{17,18}$, this whitening does not result from the formation of chromophoric groups, but it is probably originated from a topological feature of the UV exposed samples, where cracks are formed on $\mathrm{PHB}_{1}$ and $\mathrm{PHB}_{2}$ surfaces. The occurrence of surface cracking was previously associated with polypropylene whitening during UV exposure ${ }^{17}$, in which the cracks increase the roughness of the surface, raising the diffuse reflectance of the visible light.

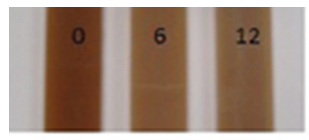

PHB:

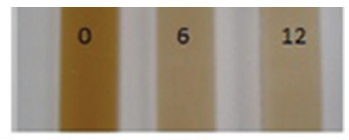

$\mathrm{PHB}_{2}$
Figure 2: Photographs of $\mathrm{PHB}_{1}$ and $\mathrm{PHB}_{2}$ tests specimens illustrating samples whitening under UV exposure. Exposing time (weeks) indicated.

The results of tensile tests for $\mathrm{PHB}_{1}$ and $\mathrm{PHB}_{2}$ unexposed and exposed up to 12 weeks are presented in Table 1, together with the results of molar mass determination. The average scissions number (SN) per macromolecule presented in Table 1 was determined using Equation 1:

$$
S N=\frac{\overline{M_{n o}}}{M_{n t}}
$$

Where: $\overline{M_{n o}}$ and $M_{n t}$ are the number-average molecular weight of the material unexposed and exposed to UV radiation for a given time, respectively.

Tensile strength and strain at break reduced with exposure time. After 12 weeks of severe weathering conditions of UV, temperature and condensed water, the tensile strength of $\mathrm{PHB}_{1}$ and $\mathrm{PHB}_{2}$ decreased $32 \%$ and $34 \%$, the strain at break decreased $30 \%$ and $42 \%$, respectively. According to work reported elsewhere ${ }^{17}$ when PHB is under UV radiation, two mechanisms might occur in parallel, i.e., macromolecular crosslinking and chain scission; one of them will be dominant and may be visualized by the change in number-average molecular weight $\left(M_{n}\right)$. Concerning the results showed in Table $1, \mathrm{M}_{\mathrm{n}}$ values of $\mathrm{PHB}_{1}$ and $\mathrm{PHB}_{2}$ decreased upon UV exposure, hence it can be deduced that the macromolecular scission is the preponderant mechanism observed here and that this is the main reason for the reduction in tensile properties. 
Table 1: Mechanical properties and $\mathrm{Mn}$ of $\mathrm{PHB}_{1}$ and $\mathrm{PHB}_{2}$ before and after exposure to UV radiation.

\begin{tabular}{|c|c|c|c|c|c|c|c|c|}
\hline & & $\mathrm{PHB}_{1}$ & & & & $\mathrm{PHB}_{2}$ & & \\
\hline $\begin{array}{l}\text { Exposure } \\
\text { time (weeks) }\end{array}$ & $\begin{array}{c}\text { Tensile } \\
\text { Strength } \\
(\mathrm{MPa})\end{array}$ & $\begin{array}{c}\text { Maximum } \\
\text { elongation (\%) }\end{array}$ & $\mathrm{M}_{\mathrm{n}}(\mathrm{g} / \mathrm{mol})$ & SN & $\begin{array}{l}\text { Tensile Strength } \\
\text { (MPa) }\end{array}$ & $\begin{array}{l}\text { Maximum } \\
\text { elongation } \\
(\%)\end{array}$ & $\mathrm{M}_{\mathrm{n}}(\mathrm{g} / \mathrm{mol})$ & $\mathrm{SN}$ \\
\hline 0 & $32.70 \pm 1.26$ & $3.17 \pm 0.17$ & 52000 & - & $34.14 \pm 0.74$ & $4.68 \pm 0.40$ & 76200 & - \\
\hline 1 & $32.32 \pm 0.62$ & $3.52 \pm 0.15$ & - & - & $34.80 \pm 0.37$ & $5.11 \pm 0.22$ & - & - \\
\hline 3 & $31.01 \pm 0.48$ & $3.13 \pm 0.09$ & - & - & $31.79 \pm 0.87$ & $4.41 \pm 0.25$ & - & - \\
\hline 6 & $30.21 \pm 0.58$ & $3.09 \pm 0.21$ & 11700 & 4.44 & $26.03 \pm 1.11$ & $3.65 \pm 0.16$ & 10800 & 7.05 \\
\hline 9 & $25.63 \pm 0.72$ & $2.54 \pm 0.08$ & - & - & $24.37 \pm 1.31$ & $3.60 \pm 0.13$ & - & - \\
\hline 12 & $22.28 \pm 0.91$ & $2.20 \pm 0.07$ & 7500 & 6.93 & $22.84 \pm 1.03$ & $2.72 \pm 0.04$ & 6400 & 11.90 \\
\hline
\end{tabular}

The HV content should be considered influencing the photodegradation of PHB. Since the HV unit is bulkier than the HB unit (see Figure 1), we have an expectation that the copolymer with a higher $\mathrm{HV}$ content $\left(\mathrm{PHB}_{2}\right)$ would be more susceptible to the degradation effects due to a higher free volume and hence a higher diffusion of oxygen and moisture. Commonly, PHB suffer degradation also by hydrolysis mechanisms ${ }^{17-21}$, i.e., under humidity environment and temperature, chain scission occurs and, together with the photodegradation effects, will contribute to the deterioration in the polymer properties. If the specimen has a more open structure as it is in $\mathrm{PHB}_{2}$ the effects of UV radiation, humidity and temperature may be more severe - as was observed for $\mathrm{PHB}_{2}$ specimens in Figure 2, and serious damage are usually observed in the mechanical properties, as shown in Table 1. Another effect is that samples with higher content of $\mathrm{HV}$ is lighter and, as a consequence, the UV radiation can reach deeper regions comparing with the darker samples with low content of HV.

Scanning electron microscopy (SEM) images of $\mathrm{PHB}_{1}$ and $\mathrm{PHB}_{2}$ surfaces photodegraded up to 12 weeks are presented on Figure 3. As can be seen in this Figure, the sample $\mathrm{PHB}_{1}$ did not show any significant changes at the surface; however; sample $\mathrm{PHB}_{2}$ presented cracks after 6 weeks of exposure and the density of the cracks increased with the exposure time. As presented before, the drop in mechanical properties was more intense for $\mathrm{PHB}_{2}$; the presence of cracks on the surface of these samples is a major reason for this behavior. The cracks formed during exposure are usually related to an increase on surface crystallinity, a phenomenon called chemi-crystallization that occurs due to rearrangement of taut molecules that are released by the chain scission events ${ }^{20}$.

Scanning electron microscopy (SEM) images of fractured surface of $\mathrm{PHB}_{1}$ and $\mathrm{PHB}_{2}$ photodegraded for 12 weeks are given in Figure 4. The fracture surface of $\mathrm{PHB}_{2}$ showed a smoother topography and similar size photodegraded zone when compared to $\mathrm{PHB}_{1}$. By SEM images it is showed an increase in photodegraded zone with exposure time. Similar trend like that observed for 12 weeks was seen in other samples, exposed for 3, 6 and 9 weeks (results not showed here) where $\mathrm{PHB}_{2}$ has larger photodegraded zones than $\mathrm{PHB}_{1}$.

In an attempt to protect $\mathrm{PHB}$ from UV effects, antioxidant and UV absorber additives were added to PHB and samples were exposed for up to 6 weeks under the same weathering conditions described before. The molecular weight distribution curves of $\mathrm{PHB}_{1}$ and $\mathrm{PHB}_{\mathrm{ABS}}$ unexposed and exposed for different times are presented in Figure 5. It is clear that the molecular weight distribution curves for $\mathrm{PHB}_{1}$ showed a significant modification in peak location and shape as exposure time is increased. However, $\mathrm{PHB}_{\mathrm{ABS}}$ did not present a major modification on the distribution curves. A consequence of this is observed on the polydispersity values $\left(\bar{M}_{w} / \bar{M}_{n}\right)$. The polydispersity of $\mathrm{PHB}_{1}$ changes from 2.6 (unexposed) to 3.7 (6 weeks exposure), whereas $\mathrm{PHB}_{\mathrm{ABS}}$ only changes from 2.2 to 2.6 .

Table 2 presents the results of tensile tests, $M_{n}$ and $S N$ for $\mathrm{PHB}_{1}$ and $\mathrm{PHB}_{\mathrm{ABS}}$. It can be observed that the mechanical properties tend to a slight decrease with the exposure time for $\mathrm{PHB}_{1}$ whereas no significant changes could be seen for $\mathrm{PHB}_{\mathrm{ABS}}$. The molecular weight decreased as much as $77.5 \%$ after 6 weeks of exposure for $\mathrm{PHB}_{1}$. On the other hand, the reduction of $\mathrm{M}_{\mathrm{n}}$ for $\mathrm{PHB}_{\mathrm{ABS}}$ was $43.8 \%$ after 6 weeks. The chain scissions in $\mathrm{PHB}_{\mathrm{Abs}}$ were $58 \%$ and $44 \%$ lower than $\mathrm{PHB}_{1}$ for analyses taken at 3 and 6 weeks, respectively. The results indicate that the UV absorber and antioxidant additives protected the PHB matrix from the UV radiation ${ }^{18,21-24}$.

Table 3 shows the crystallinity degree $\left(X_{c}\right)$ of the samples calculated by XRD before and after exposure to UV radiation. After three weeks $\mathrm{PHB}_{1}, \mathrm{PHB}_{2}$ and $\mathrm{PHB}_{\mathrm{ABS}}$ presented an increasing on the $\mathrm{X}_{\mathrm{c}}$ values followed by drop until 12 weeks. The first phenomenon is very known and called chemi-crystallization, it has been reported in the literature ${ }^{20}$ and usually takes place when polymers are exposed to UV radiation. The chemi-crystallization occurs with degraded molecules (decreased on molecular weight) rearrange themselves in the form of crystals. It could be happened because the temperature inside the UV chamber $\left(50-60^{\circ} \mathrm{C}\right)$ was higher enough to allow the cold crystallization mechanisms to develop ${ }^{9}$. After longer periods of exposure, it is possible that the chain becomes too defective by the presence of groups containing oxygen and, hence, further organization may be more difficult ${ }^{20}$. Destruction of crystals by the degradation effects has also been reported ${ }^{25}$. In the case of $\mathrm{PHB}_{\mathrm{ABS}}$ the values of $X_{c}$ increased until 6 weeks indicating that the level of the scissions was not enough to hindering the chemicrystallization phenomenon. These results are consistent with molecular weight and mechanical properties, indicating that the UV absorber and antioxidant acted very well in PHB matrix. 


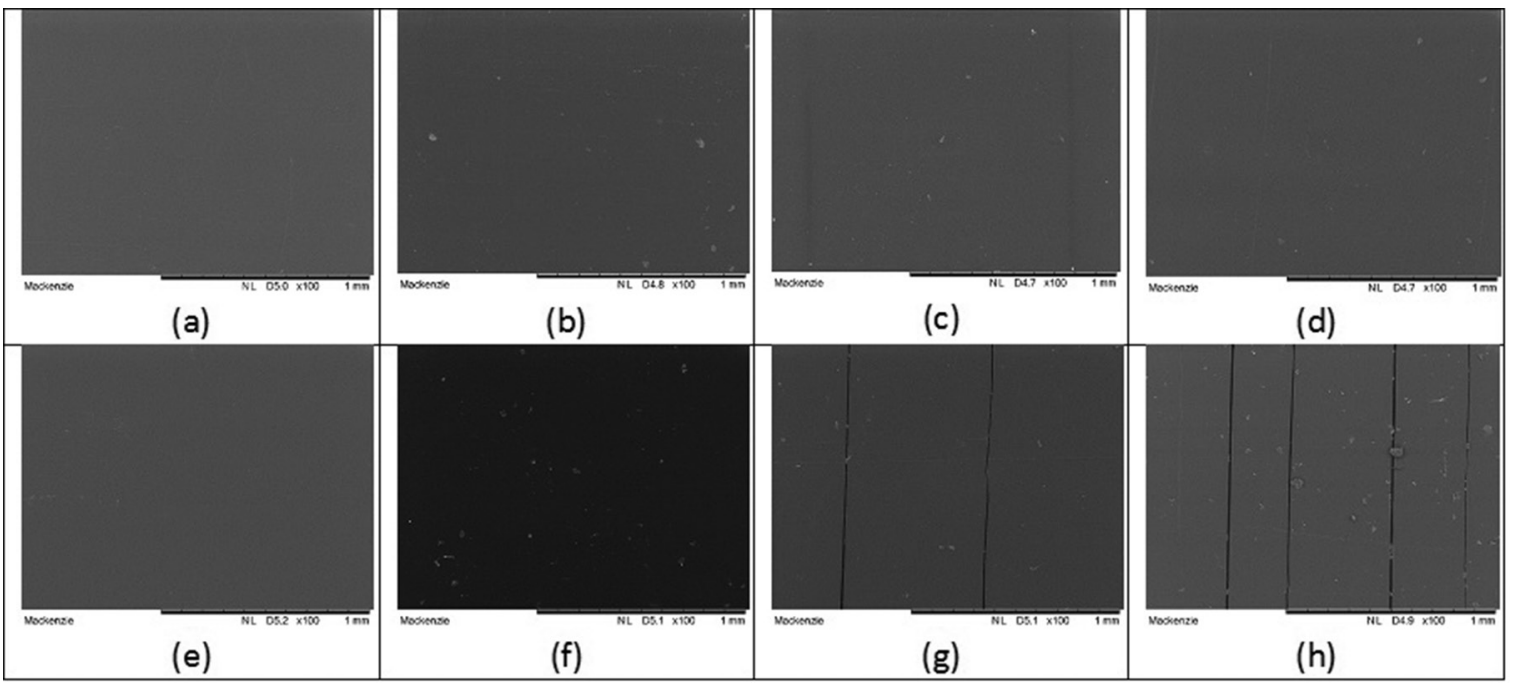

Figure 3: Scanning electron microscopy (SEM) images of $\mathrm{PHB}_{1}$ non-exposed (a) and exposed for 3 (b), 6 (c) and 12 weeks (d); and PHB non-exposed (e) and exposed for 3 (f), 6 (g) and 12 weeks (h).
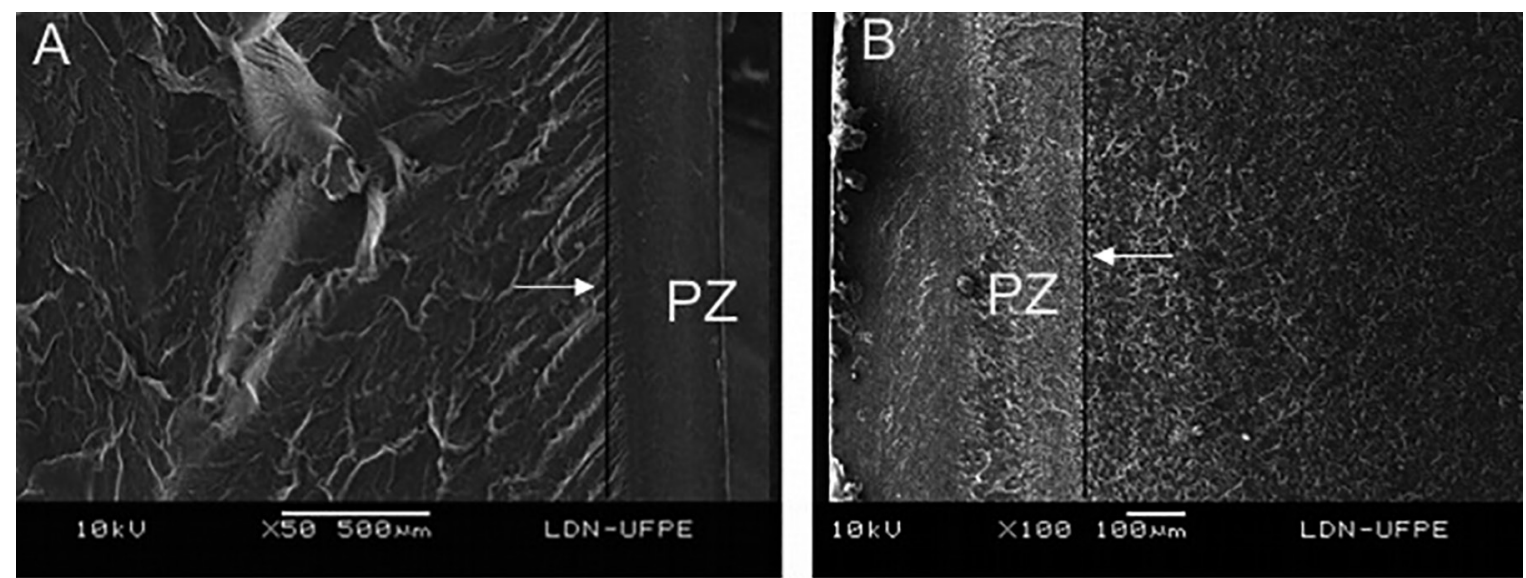

Figure 4: SEM images of fractured surface of $\mathrm{PHB}_{1}(\mathrm{a})$ and $\mathrm{PHB}_{2}$ (b) exposed to UV radiation during 12 weeks. The arrows indicate the interface between the degraded and the not-degraded material. (PZ: Photodegradaded Zone)
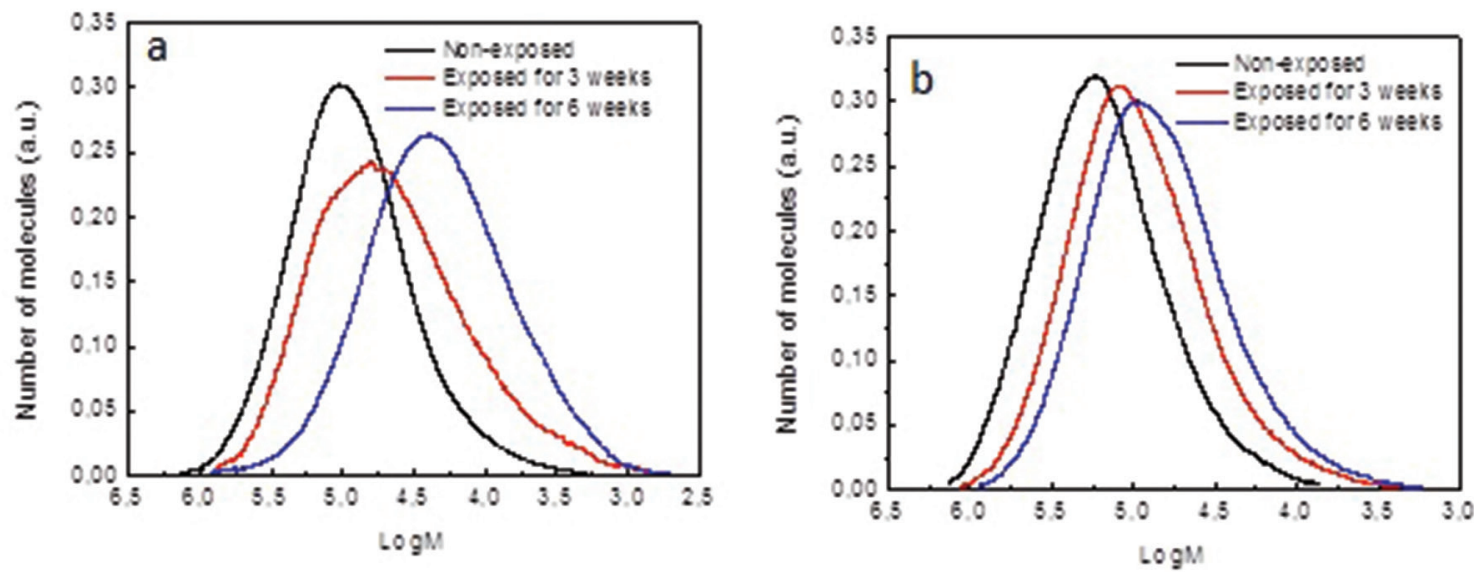

Figure 5: Molecular weight distribution curves of $\mathrm{PHB}_{1}$ (a) and $\mathrm{PHB}_{\mathrm{ABS}}$ (b) not exposure and exposed for different times.

\section{Conclusion}

The results presented in this work showed that there is a significant difference on the photodegradation damages of PHB depending on its HV content. This difference is not only due to the chemical structure but also to the color of the samples. The PHB with a higher HV content 
Table 2: Mechanical properties and of $\mathrm{PHB}$ and $\mathrm{PHB}_{\mathrm{ABS}}$ before and after exposure to UV radiation for different times.

\begin{tabular}{|c|c|c|c|c|c|c|c|c|}
\hline \multirow[b]{2}{*}{$\begin{array}{l}\text { Exposure } \\
\text { time (weeks) }\end{array}$} & \multicolumn{4}{|c|}{$\mathrm{PHB}_{1}$} & \multicolumn{4}{|c|}{$\mathrm{PHB}_{\mathrm{ABS}}$} \\
\hline & $\begin{array}{c}\text { Tensile Strength } \\
\text { (MPa) }\end{array}$ & $\begin{array}{c}\text { Maximum } \\
\text { Elongation (\%) }\end{array}$ & $\mathrm{M}_{\mathrm{n}}(\mathrm{g} / \mathrm{mol})$ & $\mathrm{SN}$ & $\begin{array}{c}\text { Tensile } \\
\text { Strength (MPa) }\end{array}$ & $\begin{array}{c}\text { Maximum } \\
\text { Elongation (\%) }\end{array}$ & $\mathrm{M}_{\mathrm{n}}(\mathrm{g} / \mathrm{mol})$ & $\mathrm{SN}$ \\
\hline 0 & $32.70 \pm 1.26$ & $3.17 \pm 0.17$ & 52000 & - & $32.15 \pm 1.12$ & $4.09 \pm 0.10$ & 85100 & - \\
\hline 1 & $32.32 \pm 0.62$ & $3.52 \pm 0.15$ & - & - & $33.05 \pm 0.37$ & $4.72 \pm 0.18$ & - & - \\
\hline 3 & $31.01 \pm 0.48$ & $3.13 \pm 0.09$ & 20600 & 2.52 & $32.68 \pm 0.29$ & $4.28 \pm 0.09$ & 57700 & 1.47 \\
\hline 6 & $30.21 \pm 0.58$ & $3.09 \pm 0.21$ & 11700 & 4.44 & $32.41 \pm 1.07$ & $3.90 \pm 0.18$ & 43800 & 1.94 \\
\hline
\end{tabular}

Table 3: Crystallinity degree $\left(\mathrm{X}_{\mathrm{c}}\right)$ of $\mathrm{PHB}_{1}, \mathrm{PHB}_{2}$ and $\mathrm{PHB}_{\mathrm{ABS}}$ before and after exposure to UV radiation for different times.

\begin{tabular}{lccc}
\hline Exposure time (weeks) & $\mathrm{PHB}_{1}$ & $\mathrm{PHB}_{2}$ & $\mathrm{PHB}_{\mathrm{ABS}}$ \\
\hline 0 & 56.2 & 51.7 & 49.8 \\
3 & 72.3 & 69.5 & 58.0 \\
6 & 64.6 & 56.7 & 59.4 \\
12 & 60.7 & 54.7 & - \\
\hline
\end{tabular}

is lighter than the PHB with a lower HV content and, as consequence; the penetration of UV radiation is deeper into the test bars. The results after 12 weeks showed that whiteness, mechanical properties, molecular weight and fracture surface damages were more accentuated on PHB with higher HV content. The additions of the UV absorber and the antioxidant additives have improved the UV stability of PHB, with a significant reduction on the photodegradation rate, as observed by mechanical properties, molecular weight and crystallinity degree. It is hoped that these results could be useful to design materials with more stability during processing and ultraviolet exposure while maintaining their characteristic of biodegradability.

\section{Acknowledgments}

The authors wish to thank PHB Industrial SA (Brazil) for supplying the raw materials, to Prof. Agnelli (UFSCar, Brazil) for injection moulding PHBs sample tests, CNPq/Brazil (MCTI/CNPq No 14/2012 Process Number: 478124/2012-0) and FAPESP/SP/Brazil for the financial support. RMRW thanks to Eduardo Brondi from PHB Industrial SA (Brazil) for discussions related to this work.

\section{References}

1. Renstad R, Karlsson S, Albertsson AC, Werner PE, Westdahl M. Influence of Processing Parameters on the Mass Crystallinity of Poly(3-hydroxybutyrate- co-3-hydroxyvalerate). Polymer International. 1997;43(3):201-209. DOI: http://dx.doi.org/10.1002/ (SICI)1097-0126(199707)43:3<201::AID-PI761>3.0.CO;2-7

2. Reddy K, Ghai R, Kalia C. Polyhydroxyalkanoates: an overview. Bioresource Technology. 2003; 87(2):137-146. DOI: http:// dx.doi.org/10.1016/S0960-8524(02)00212-2

3. Cimmino S, Iodice P, Martuscelli E, Silvestre C. Poly(3-D(-) hydroxybutyrate)/atactic poly(methylmethacrylate) blends: Morphology, miscibility and crystallization relationships. Thermochimica Acta. 1998;321(1-2):89-98. DOI: http://dx.doi. org/10.1016/S0040-6031(98)00444-4
4. El-Hadi A, Schnabel R, Straube E, Müller G, Henning S. Correlation between degree of crystallinity, morphology, glass temperature, mechanical properties and biodegradation of poly (3-hydroxyalkanoate) PHAs and their blends. Polymer Testing. 2002;21(6):665-674. DOI: http://dx.doi.org/10.1016/ S0142-9418(01)00142-8

5. Bucci DZ, Tavares LBB, Sell I. PHB packaging for the storage of food products. Polymer Testing. 2005;24(5):564-571. DOI: http://dx.doi.org/10.1016/j.polymertesting.2005.02.008

6. Wellen RMR, Rabello MS, Araújo Júnior IC, Fechine GJM, Canedo EL. Melting and crystallization of poly(3-hydroxybutyrate): effect of heating/cooling rates on phase transformation. Polimeros. 2015;25(3):296-304. DOI: http://dx.doi.org/10.1590/0104-1428.1961

7. Wellen RMR, Rabello MS, Fechine GJM, Canedo EL. The melting behavior of poly(3-hydroxybutyrate) by DSC. Reproducibility study. Polymer Testing. 2015;32(2):215-220. DOI: http://dx.doi. org/10.1016/j.polymertesting.2012.11.001

8. Wellen RMR, Canedo EL, Lima CAV, Araújo Júnior IC, Almeida YMB, Rabello MS. The Effect of Polystyrene on the Crystallization of Poly(3-hydroxybutyrate). Materials Research. 2015;18(2):235-239. DOI: http://dx.doi.org/10.1590/15161439.242213

9. Wellen RMR, Rabello MS, Canedo EL. Melting and crystallization of poly(3-hydroxybutyrate)/carbon black compounds. Effect of heating and cooling cycles on phase transition. Journal of Materials Research. 2015;30(21):3211-3226. DOI: http://dx.doi. org/10.1557/jmr.2015.287

10. Farias RF, Canedo EL, Wellen RMR, Rabello MS. Environmental Stress Cracking of Poly(3-hydroxibutyrate) Under Contact with Sodium Hydroxide. Materials Research . 2015;18(2):258-266. DOI: http://dx.doi.org/10.1590/1516-1439.286114

11. Carlo EC, Borges APB, Pompermayer LG, Martinez MMM, Eleotério RB, Nehme RC, et al. Composite for the fabrication of resorbable implants for osteosynthesis: biocompatibility evaluation in rabbits. Ciência Rural. 2009;39(1):135-140. DOI: http://dx.doi.org/10.1590/S0103-84782008005000036

12. Chen GQ, Wu Q. The application of polyhydroxyalkanoates as tissue engineering materials. Biomaterials. 2005;26(33):65656578. DOI: http://dx.doi.org/10.1016/j.biomaterials.2005.04.036

13. Modi S, Koelling K, Vodovotz Y. Assessment of PHB with varying hydroxyvalerate content for potential packaging applications. European Polymer Journal. 2011;47(2):179-186. DOI: http:// dx.doi.org/10.1016/j.eurpolymj.2010.11.010 
14. Bahari K, Mitomo H, Enjoji T, Yoshii F, Makuuchi K. Degradability of poly(3-hydroxybutyrate) and its copolymer grafted with styrene by radiation. Polymer Degradation and Stability. 1998;61(2):245-252. DOI: http://dx.doi.org/10.1016/ S0141-3910(97)00147-X

15. Harding KG, Dennis JS, von Blottnitz H, Harrison ST. Environmental analysis of plastic production processes: comparing petroleum-based polypropylene and polyethylene with biologically-based poly-beta-hydroxybutyric acid using life cycle analysis. Journal of Biotechnology. 2007;130(1):5766. PMID: 17400318

16. Rhim J, Park HM, Ha CS. Bio-nanocomposites for food packaging applications. Progress in Polymer Science. 2013;38(10-11):16291652. DOI: http://dx.doi.org/10.1016/j.progpolymsci.2013.05.008

17. Sadi RK, Fechine GJM, Demarquette NR. Photodegradation of poly(3-hydroxybutyrate). Polymer Degradation and Stability. 2010; 95(12):2318-2327. DOI: http://dx.doi.org/10.1016/j. polymdegradstab.2010.09.003

18. Sadi RK, Fechine GJM, Demarquette NR. Effect of prior photodegradation on the biodegradation of polypropylene/ poly(3-hydroxybutyrate) blends. Polymer Engineering \& Science. 2013;53(10):2109-2122. DOI: http://dx.doi.org/10.1002/pen.23471

19. Fernandes LL, Freitas CA, Demarquette NR, Fechine GJM. Photodegradation of thermodegraded polypropylene/highimpact polystyrene blends: Mechanical properties. Journal of Applied Polymer Science. 2011;120(2):770-779. DOI: http:// dx.doi.org/10.1002/app.33096
20. Rabello MS, White JR. Crystallization and melting behaviour of photodegraded polypropylene - I. Chemi-crystallization. Polymer. 1997;38(26):6379-6387. DOI: http://dx.doi.org/10.1016/ S0032-3861(97)00213-9

21. Freier T, Kunze C, Nischan C, Kramer S, Sternberg K, Saß M, et al. In vitro and in vivo degradation studies for development of a biodegradable patchbased on poly(3-hydroxybutyrate). Biomaterials. 2002;23(13):2649-2657. PMID: 12059014 DOI: http://dx.doi.org/10.1016/S0142-9612(01)00405-7

22. Kasuya K, Inoue Y, Yamada K, Doi Y. Kinetics of surface hydrolysis of poly[(R)-3-hydroxybutyrate] film by PHB depolymerase from Alcaligenes faecalis Tl. Polymer Degradation and Stability. 1995;48(1):167-174. DOI: http://dx.doi.org/10.1016/01413910(95)00026-I

23. La Mantia FP. Recycling of heterogeneous plastics wastes. II The role of modifier agents. Polymer Degradation and Stability. 1993;42(2):213-218. DOI: http://dx.doi.org/10.1016/01413910(93)90114-X

24. Parra DF, Fusaro J, Gaboardi F, Rosa DS. Influence of poly (ethylene glycol) on the thermal, mechanical, morphological, physical-chemical and biodegradation properties of poly (3-hydroxybutyrate). Polymer Degradation and Stability. 2006;91(9):1954-1959. DOI: http://dx.doi.org/10.1016/j. polymdegradstab.2006.02.008

25. Vaughan AS, Stevens GC. On radiation effects in poly(ethylene terephtalate): a comparison with poly(ether ether ketone). Polymer. 1995;36(8):1541-1547. DOI: http://dx.doi.org/10.1016/00323861(95)98997-2 